\title{
RISK STRATIFICATION OF ACUTE UPPER GI BLEEDING BY ROCKALL, GLASGOW BLATCHFORD AND AIMS 65 SCORES
}

\author{
By
}

\section{Amr Abd El-Monem Mohamed El-Mohr, Mohamed Amer Afify and Sherif Ali Abd El-Aziz}

Hepato-Gastroenterology and Infectious Disease, Al-Azhar University, Cairo, Egypt

Nasser Institute hospital (NIH) for Research and Treatment, Cairo, Egypt

*Corresponding author: Amr Abd El Monem Mohamed El Mohr

Mobile: (+2) 01000404786, E-mail: amrelmoher9@gmail.com

\begin{abstract}
Background: Prognostic scales should be used for early stratification of patients according to risk. Several risk scores have been developed, most of which include endoscopic findings.

Objective: To compare three scores "Rockall, Blatchford and AIMS65 scores" to identify the most accurate score used in predicting unfavorable outcomes during patient hospitalization, and for about 1 week after discharge.

Patients and methods: A prospective study was conducted on Egyptian patients presented by upper gastrointestinal bleeding, (UGIB) recruited from the emergency department (ED) of Nasser institute hospital for research and treatment, over a period from January 2019 to July 2019.

Results: About half of cases had chronic liver disease. The most frequent clinical condition was Melena; present in about half of cases. Stigmata were in more than half of cases. Cases with need for interventional endoscopy had significant higher hepatic disease, severe comorbidities, melena, syncope, shock and worser laboratories\& endoscopic findings.
\end{abstract}

Conclusion: Risk stratification and decision to perform interventions including therapeutic endoscopy is often a subjective matter.

Key words: Risk scoring systems, upper gastrointestinal bleeding, upper endoscopy, risk stratification.

\section{INTRODUCTION}

UGIB is a gastrointestinal emergency that can result in significant morbidity, mortality, and use of health care resources (Thandassery et al., 2015).

The etiology of UGIB can vary from trivial causes like gastric erosions to potentially fatal conditions like aortoenteric fistula. UGIB therefore raises significant concern upon presentation in emergency department (Monteiro et al., 2016).

Many risk factors are known to influence the outcome in UGIB setting. Age, comorbidities, presence of shock, endoscopic diagnosis, hemoglobin values at the time, stigmata of recent hemorrhage and need for a blood transfusion have all been described as significant risk factors for rebleeding and death (Nahon et al., 2012). 
In order to stratify the risk of complications, rebleeding, need of clinical intervention or death, several clinical scores are in use. Although recommended in the prevailing guidelines, they are erratically applied in the clinical practice (Barkun et al., 2010 and Dworzynski et al., 2012).

An ideal risk score is one that is easy to calculate, contain easy access variables, have high accuracy in predicting relevant outcomes, distinguish low-risk from highrisk patients and can be measured early after presentation with UGIB (Stanley et al., 2012).

Risk scores based on clinical and endoscopic variables have been developed for patients with acute Upper gastrointestinal bleeding, the most widely used scoring systems are Glasgow Blatchford score (GBS), Rockall, AIMS65 scoring systems (Bozkurt et al., 2015).

The Rockall score (RS) which ranges from 0 to 11, was developed in 1996 to predict mortality due to UGIB. This score incorporates five variables: Age, hemodynamic status, patient's comorbidities, endoscopic diagnosis and presence of major stigmata of recent hemorrhage. The pre endoscopic Rockall score is calculated without the endoscopic findings, and only includes 3clinical comorbid disease. A maximum score of 7 is possible (Stanley, 2012).

\section{Glasgow-Blatchford Score}

(GBS) incorporates 8 clinical or laboratorial variables (heart rate, hemoglobin value, blood urea nitrogen, systolic blood pressure, melena occurrence, syncope, hepatic disease, or heart failure). The GBS ranges from 0 to 23 , with higher scores indicating higher likelihood of a need for endoscopic intervention (Laine, 2016).

An acronymic risk score named AIMS65 which incorporates albumin level $<3.0 \mathrm{~g} / \mathrm{dl}(\mathrm{A})$, international normalized ratio (INR) $>1.5$ (1), altered mental status (M), systolic blood pressure < $90 \mathrm{mmHg}$ (S), and age >65 years (65) (Saltzman et al., 2011).

Early recognition and accurate rebleeding risks may increase the efficiency of patient care while providing guidance for emergency physicians for making final decisions (hospital admission, intensive care unit admission, discharge from ED) (Bozkurt et al., 2015).

The aim of this study was to compare three scores "Rockall, Blatchford and AIMS65 scores" to identify the most accurate score used in predicting unfavorable outcomes during patient hospitalization and for about 1 week after discharge.

\section{PATIENTS AND METHODS}

This study was conducted on 120 adult Egyptian patients presented by symptoms of acute UGIB (hematemsis and melena) at ED of Nasser Institute Hospital. Patients underwent upper endoscopy within first day from an attack of UGIB. All patients signed a written informed consent prior to enrollment into this study.

The study aimed to compare Blatchford score with rockall scores (clinical and complete) and AIMS65 score to identify the most accurate score used in predicting unfavorable outcomes during hospitalization and 1 week after discharge.

\section{Exclusion criteria:}

- Refuse to participate in this study. 
- Patients who developed upper gastrointestinal bleeding while an inpatient for another reason.

- Patients who did not undergo esophago-gastroduodenoscopy (EGD).

- Patients whose bleeding was not of upper gastrointestinal origin.

Investigations and tools used in the study were:

- Complete history talking including anticoagulant.

- Clinical examination.

- Blood samples before any medications or blood transfusion for Laboratory assessment.

- Proton pump inhibitors (PPIs) were not routinely given to all admitted patients before endoscopy. All patients with suspected varices received IV antibiotics and vasopressors. Vasopressors were in form of a 50ugi.v.bolus of octreotide or terlipressin on admission, followed by an infusion of $1 \mathrm{mg}$ in $55 \mathrm{ml}$ of normal saline at a rate of $3 \mathrm{ml} / \mathrm{h}$. After endoscopy, administration of high dose PPIs by intravenous bolus followed by infusion to patients with high risk ulcer stigmata that required endoscopic treatment, and to other selected patients depending on clinical judgment.

- Upper gastrointestinal endoscopy were performed for diagnosis, recording endoscopic findings and proper management if stigmata of recent hemorrhage were seen. Esophageal varices were either injected with ethanolamine or banded, depending on the clinical setting and availability. While patients with gastric varices, endoscopic injection with histoacryl was performed. For patients with peptic ulcer disease, endoscopic injection therapy (adrenaline 1:100,000) into and around the bleeding point, thermal contact or/\& clips were recommended in the presence of stigmata of recent hemorrhage.

- Prospective assessment of all admissions were due to either esophageal varices or peptic ulceration. Peptic ulceration defined by the individual endoscopist as any lesion seen to possess unequivocal depth. Erosions classified as any other break in the mucosa. A cherry-red spot, red whale marks and hematocystic spots were considered being equivalent to a dark spot and therefore has a score of 0 . Rebleeding defined as overt fresh bleeding after initial stabilization, or a fall in blood pressure after initial stabilization or a fall in $\mathrm{Hb}$ of more than $2 \mathrm{~g}$ within 24 hours.

- Admission RS, Full RS, GBS and AMIS65 systems were calculated for each patient. Patient's age, systolic blood pressure, pulse rate and presence of comorbid diseases were recorded for Admission RS. Endoscopic findings (diagnosis and stigmata of recent bleeding) were recorded as additional variables of full RS system. Pulse rate, systolic blood pressure, blood urea nitrogen, hemoglobin, presentation of melena, hepatic disease, and cardiac failure were recorded as variables of GBS system.

Albumin, INR, Alteration in mental status, systolic blood pressure and age were recorded as variables of AIMS65 system. 
- Abdominal Ultrasonography for radiological criteria of portal hypertension (spleen size, portal vein diameter and ascites).

- Data were collected pertaining to clinical outcomes during hospitalization and 1 week after discharge.

\section{Statistical Analysis:}

The collected data were coded, tabulated, and statistically analyzed using IBM SPSS statistics (Statistical Package for Social Sciences) software version 18.0, IBM Corp., Chicago, USA, 2009.

Descriptive statistics were done for quantitative data as minimum\& maximum of the range as well as mean $\pm \mathrm{SD}$ (standard deviation) for quantitative normally distributed data, while it was done for qualitative data as number and percentage.

Inferential analyses were done for quantitative variables using Shapiro-Wilk test for normality testing, independent $\mathrm{t}$ test in cases of two independent groups with normally distributed data. In qualitative data, inferential analyses for independent variables were done using Chi square test for differences between proportions. ROC curve was used to evaluate the performance of different tests differentiate between certain groups. The level of significance was taken at $\mathrm{P}$ value $<0.050$.

\section{Diagnostic characteristics were calculated as follows:}

Sensitivity $=($ True positive test $/$ Total positive golden) x 100

Specificity $=($ True negative test $/$ Total negative golden) $\mathrm{x} 100$

Diagnostic accuracy $=([$ True positive test + True negative test] / Total cases) x 100

\section{RESULTS}

Blatchford and AMS65 had highest significant diagnostic performance and characteristics in prediction of need for interventional endoscopy (Table 1 and figure 1).

Table (1): Diagnostic performance of scores in prediction of need for interventional endoscopy

\begin{tabular}{|c|c|c|c|c|c|c|}
\hline Scores & AUC & P & Cutoff & Sensitivity & Specificity & Accuracy \\
\hline $\begin{array}{c}\text { Incomplete } \\
\text { Rockall }\end{array}$ & 0.579 & 0.141 & $\geq 3.0$ & $19.2 \%$ & $100.0 \%$ & $65.0 \%$ \\
\hline Complete Rockall & 0.516 & 0.761 & $\geq 3.0$ & $75.0 \%$ & $41.2 \%$ & $55.8 \%$ \\
\hline Blatchford & 0.722 & $<\mathbf{0 . 0 0 1}$ & $\geq 12.0$ & $46.2 \%$ & $86.8 \%$ & $69.2 \%$ \\
\hline AMS65 & 0.728 & $<\mathbf{0 . 0 0 1}$ & $\geq 2.0$ & $55.8 \%$ & $82.4 \%$ & $70.8 \%$ \\
\hline
\end{tabular}




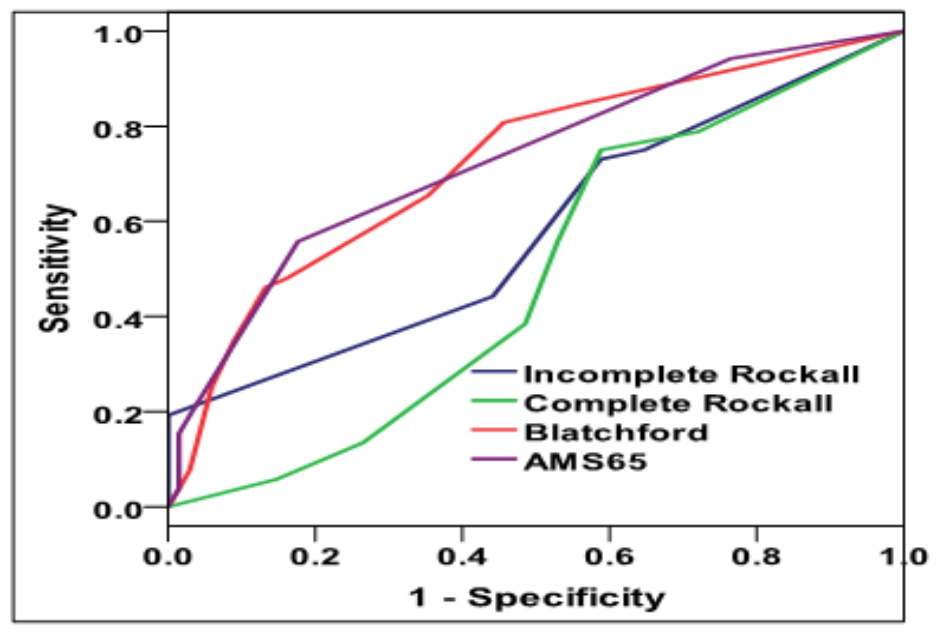

Figure (1): ROC curve for scores in prediction of need for interventional endoscopy

Blatchford had highest diagnostic performance and characteristics in prediction of need for blood transfusion followed by AMS65 (Table 2 and figure 2).

Table (2): Diagnostic performance of scores in prediction of need for blood transfusion

\begin{tabular}{|l|c|c|c|c|c|c|}
\hline \multicolumn{1}{|c|}{ Scores } & AUC & P & Cutoff & Sensitivity & Specificity & Accuracy \\
\hline $\begin{array}{l}\text { Incomplete } \\
\text { Rockall }\end{array}$ & 0.640 & $\mathbf{0 . 0 1 0}$ & $\geq 3.0$ & $60.4 \%$ & $66.7 \%$ & $64.2 \%$ \\
\hline Complete Rockall & 0.519 & 0.728 & $\geq 6.0$ & $25.0 \%$ & $81.9 \%$ & $59.2 \%$ \\
\hline Blatchford & 0.745 & $<\mathbf{0 . 0 0 1}$ & $\geq 11.0$ & $56.3 \%$ & $87.5 \%$ & $75.0 \%$ \\
\hline AMS65 & 0.660 & $\mathbf{0 . 0 0 3}$ & $\geq 2.0$ & $52.1 \%$ & $77.8 \%$ & $67.5 \%$ \\
\hline
\end{tabular}

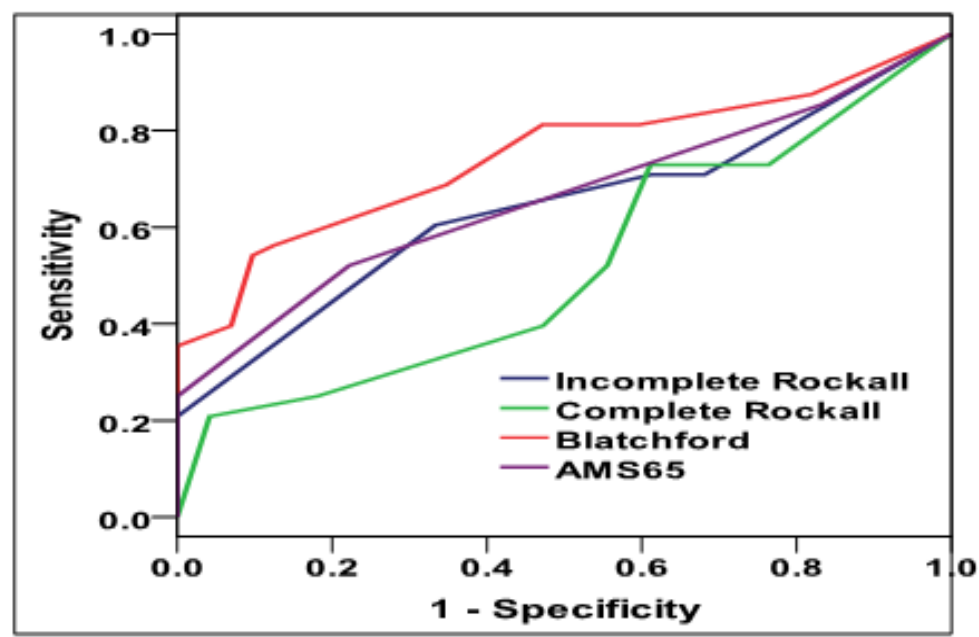

Figure (2): ROC curve for scores in prediction of need for blood transfusion 
AMS65 score had highest diagnostic performance and characteristics in prediction of ICU admission in hospital followed by Blatchford (Table 3 and figure 3).

Table (3): Diagnostic performance of scores in prediction of ICU admission in hospital

\begin{tabular}{|l|c|c|c|c|c|c|}
\hline \multicolumn{1}{|c|}{ Scores } & AUC & P & Cutoff & Sensitivity & Specificity & Accuracy \\
\hline $\begin{array}{l}\text { Incomplete } \\
\text { Rockall }\end{array}$ & 0.677 & $\mathbf{0 . 0 0 1}$ & $\geq 1.0$ & $88.6 \%$ & $42.1 \%$ & $59.2 \%$ \\
\hline Complete Rockall & 0.608 & $\mathbf{0 . 0 4 9}$ & $\geq 2.0$ & $95.5 \%$ & $36.8 \%$ & $58.3 \%$ \\
\hline Blatchford & 0.898 & $<\mathbf{0 . 0 0 1}$ & $\geq 11.0$ & $70.5 \%$ & $93.4 \%$ & $85.5 \%$ \\
\hline AMS65 & 0.923 & $<\mathbf{0 . 0 0 1}$ & $\geq 2.0$ & $86.4 \%$ & $96.1 \%$ & $92.5 \%$ \\
\hline
\end{tabular}

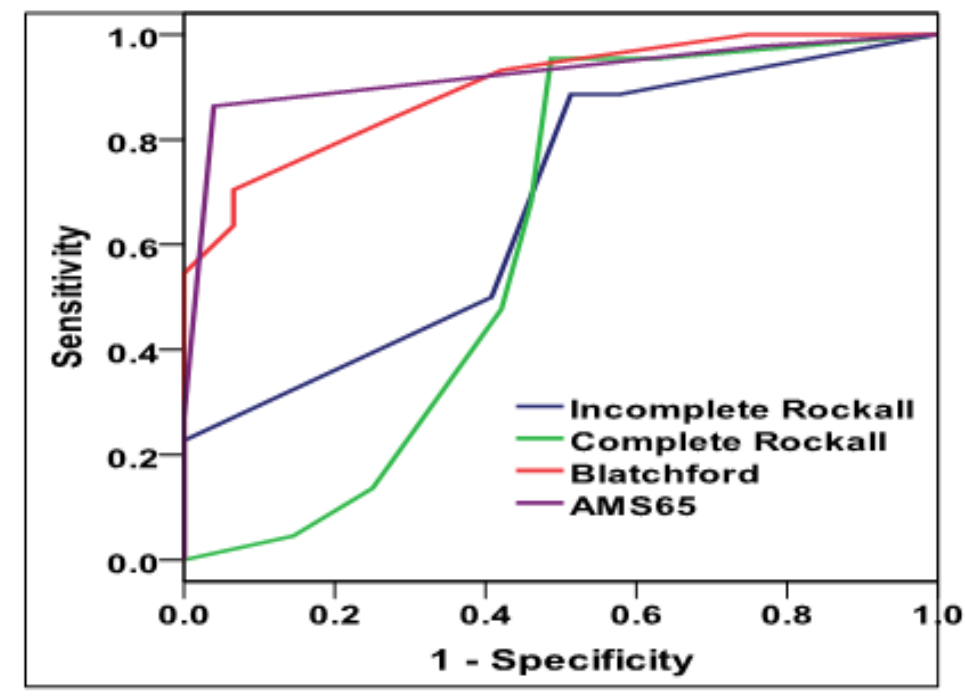

Figure (3): ROC curve for scores in prediction of ICU admission in hospital

AMS65 score had highest diagnostic performance and characteristics in prediction of rebleeding in hospital followed by Blatchford (Table 4 and figure 4).

Table (4): Diagnostic performance of scores in prediction of rebleeding in hospital

\begin{tabular}{|l|c|c|c|c|c|c|}
\hline \multicolumn{1}{|c|}{ Scores } & AUC & $\mathbf{P}$ & Cutoff & Sensitivity & Specificity & Accuracy \\
\hline $\begin{array}{l}\text { Incomplete } \\
\text { Rockall }\end{array}$ & 0.678 & $\mathbf{0 . 0 0 1}$ & $\geq 1.0$ & $90.2 \%$ & $41.8 \%$ & $58.3 \%$ \\
\hline Complete Rockall & 0.600 & 0.073 & $\geq 2.0$ & $97.6 \%$ & $36.7 \%$ & $57.5 \%$ \\
\hline Blatchford & 0.914 & $<\mathbf{0 . 0 0 1}$ & $\geq 11.0$ & $75.6 \%$ & $93.7 \%$ & $87.5 \%$ \\
\hline AMS65 & 0.947 & $<\mathbf{0 . 0 0 1}$ & $\geq 2.0$ & $92.7 \%$ & $96.2 \%$ & $95.0 \%$ \\
\hline
\end{tabular}




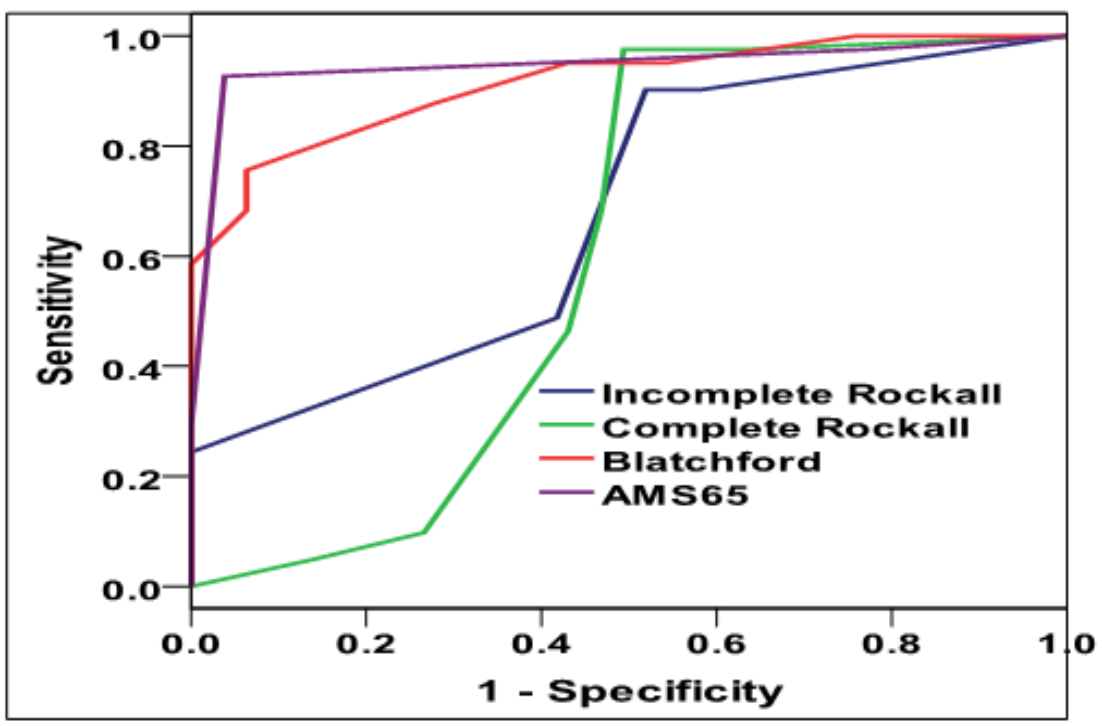

Figure (4): ROC curve for scores in prediction of rebleeding in hospital

AMS65 score had highest diagnostic performance and characteristics in prediction of death in hospital, followed by Blatchford (Table 5 and figure 5).

Table (5): Diagnostic performance of scores in prediction of death in hospital

\begin{tabular}{|l|c|c|c|c|c|c|}
\hline \multicolumn{1}{|c|}{ Scores } & AUC & $\mathbf{P}$ & Cutoff & Sensitivity & Specificity & Accuracy \\
\hline $\begin{array}{l}\text { Incomplete } \\
\text { Rockall }\end{array}$ & 0.844 & $<\mathbf{0 . 0 0 1}$ & $\geq 3.0$ & $90.9 \%$ & $60.6 \%$ & $63.3 \%$ \\
\hline Complete Rockall & 0.528 & 0.764 & $\geq 2.0$ & $100.0 \%$ & $27.5 \%$ & $34.2 \%$ \\
\hline Blatchford & 0.980 & $<\mathbf{0 . 0 0 1}$ & $\geq 13.0$ & $100.0 \%$ & $88.1 \%$ & $75.0 \%$ \\
\hline AMS65 & 0.982 & $<\mathbf{0 . 0 0 1}$ & $\geq 2.0$ & $100.0 \%$ & $72.5 \%$ & $89.2 \%$ \\
\hline
\end{tabular}

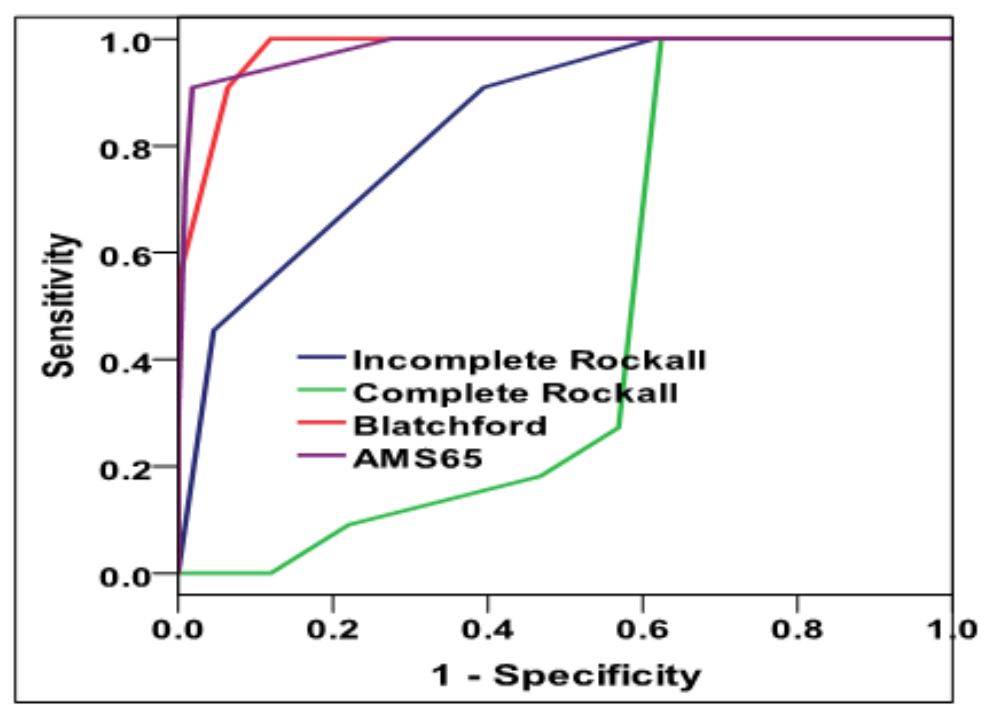

Figure (5): ROC curve for scores in prediction of death in hospital 
AMS65 score had highest diagnostic performance and characteristics in prediction of rebleeding after one week, followed by Blatchford (Table 6 and figure 6).

Table (6): Diagnostic performance of score in prediction of rebleeding after one week

\begin{tabular}{|l|c|c|c|c|c|c|}
\hline \multicolumn{1}{|c|}{ Scores } & AUC & P & Cutoff & Sensitivit & Specificity & Accuracy \\
\hline $\begin{array}{l}\text { Incomplete } \\
\text { Rockall }\end{array}$ & 0.562 & 0.392 & $\geq 1.0$ & $84.2 \%$ & $18.8 \%$ & $31.7 \%$ \\
\hline Complete Rockall & 0.577 & 0.286 & $\geq 2.0$ & $100.0 \%$ & $29.7 \%$ & $40.8 \%$ \\
\hline Blatchford & 0.725 & $\mathbf{0 . 0 0 2}$ & $\geq 7.0$ & $100.0 \%$ & $18.8 \%$ & $31.7 \%$ \\
\hline AMS65 & 0.842 & $<\mathbf{0 . 0 0 1}$ & $\geq 1.0$ & $100.0 \%$ & $33.7 \%$ & $41.7 \%$ \\
\hline
\end{tabular}

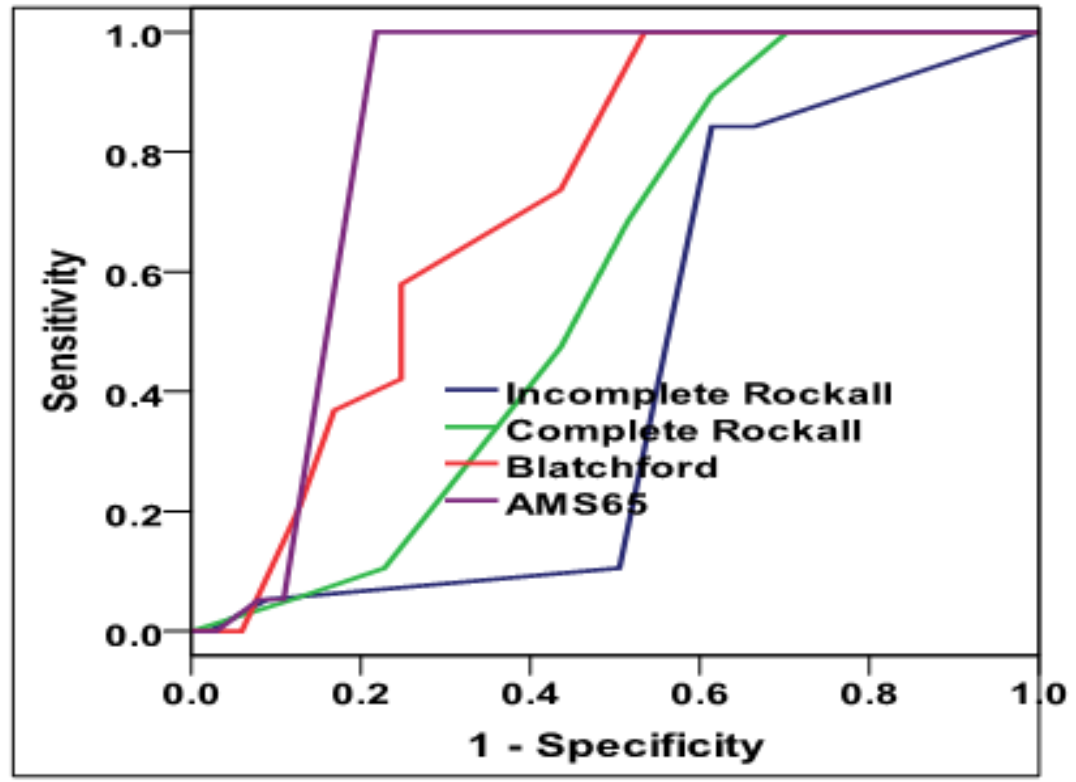

Figure (6): ROC curve for scores in prediction of rebleeding after one week

\section{DISCUSSION}

According to the American Society of Gastrointestinal Endoscopy guidelines, use of prognostic scoring systems is recommended for follow up and treatment selection in patients with UGIB (Hwang, 2012).

One hundred and twenty adult patients presenting with attack of UGIB were included in our study. All patients received endoscopic evaluation within 24 hours of presentation and follow up for one week after discharge.

Clinical, complete RS, GalsgowBlatchford and AIMS65 scores were calculated for all cases.

According to our study, Blatchford score had highest diagnostic performance and characteristics in prediction of need for blood transfusion followed by AIMS65. AIMS65 score had highest diagnostic performance and characteristics in prediction of ICU admission in hospital 
followed by Blatchford. Blatchford and AIMS65 had highest significant diagnostic performance and characteristics in prediction of need for interventional endoscopy. AIMS65 score had highest diagnostic performance and characteristics in prediction of rebleeding in hospital followed by Blatchford. AIMS65 score had highest diagnostic performance and characteristics in prediction of death in hospital followed by Blatchford score. AIMS65 score had highest diagnostic performance and characteristics in prediction of rebleeding after one week followed by Blatchford score. Our study revealed AIMS65 score was superior to Blatchford, clinical Rockall and complete rockall scores in identifying patients who were likely to need ICU admission and interventional endoscopy, while Blatchford score was superior to AIMS65, clinical Rockall and complete Rockall scores in identifying patients who were likely to need for blood transfusion.

These results came in accordance with previous studies.

Budimir et al. (2016) studied patients with variceal bleeding, admitted during the study period, most frequently with alcoholic cirrhosis. The GBS was superior in predicting the need for blood transfusion. Robertson et al. (2016) studied patients with acute UGIB the AIMS65 score was superior to both the GBS and the preendoscopic Rockall score and equivalent to the full Rockall score in predicting in patient mortality. The AIMS65 score was superior to all other scores in predicting the need for ICU admission and length of hospital stay. GBS was superior to all other scores for predicting blood transfusion.
Stanley et al. (2017) studied patients with UGIB. Comparison of clinical Rockall, AIMS65. Glasgow Blatchford, full Rockall and PNED scores. The result revealed, the GBS was best at predicting intervention or death compared with the full Rockall score, PNED score, clinical Rockall score and AIMS65 score. The GBS was better at predicting endoscopic treatment than the AIMS65 and clinical RS. The PNED and AIMS65 scores were best at predicting mortality, both superior to clinical RS and GBS.

Kalkan et al. (2017) studied elderly patients with upper gastrointestinal bleeding. Pre and post- endoscopic Rockll, Glasgow- Blatchford and AIMS65 scores were calculated. Pre and post endoscopic Rockall scores were superior to the GBS for predicting mortality likewise pre and post endoscopic Rockall scores were superior to GBS for predicting rebleeding.

Espinoza-Ríos, (2016) studied patients of UGIB "AIMS65 superior in evaluation of mortality". "GBS superior in evaluation of rebleeding", GBS was superior in evaluation of need for transfusion".

Abougergi et al. (2016) stated that the AIMS65 score was superior to GBS in predicting in hospital mortality "agree our results" and length of stay. The scores were similar in predcting in hospital rebleeding "disagree our results" and 30 day mortality.

Hyett et al. (2013), in there retrospective cohort study, compared the AIMS65 score with GBS in predcting UGIB outcomes. The AIMS65 score was superior in predicting inpatient mortality "agree our results". The 2 scores were similar in predcting the clinical end point 
"disagree our results". The GBS was superior in predicting blood transfusion.

Yaka et al. (2015) compared GBS with AIMS65 for risk stratification in UGIB. The GBS and AIMS65 were similar with respect to predicting in- hospital mortality "disagree our results" The GBS was superior to AIMS65 in identifying high risk patients the GBS was also more accurate than the AIMS65 in predicting the need for blood transfusion and intervention.

Park et al. (2016) calculated AIMS65 score clinical, full Rockall scores and GBS in none variceal upper gastrointestinal bleeding (NVUGIB) in single center retrospectively. The AIMS65 score was useful for predicting the 30 day mortality, the need for endoscopic intervention and for transfusion. The full Rockall score was superior to the AIMS65, GBS and clinical Rockall for Predicting endoscopic intervention "disagree" and GBS was superior to the AIMS65, full Rockall score and complete Rockall score for predicting the transfusion requirement.

Kim et al. (2019) studied patients with NVUGIB. The AIMS65 score, GBS, Rockall score and clinical Rockall score were used to stratify patients based on their bleeding risk. The AIMS65 was superior to the GBS, the RS and clinical Rockall in predicting the hospital mortality. The AUC value of the AIMS65 was not significantly different from the other scoring systems in predicting of rebleeding, endoscopic intervention or ICU admission.

The reasons for differences in cutoff values can including ethnicity, UGIB aetiology, period of follow up and number of patients.

\section{CONCLUSION}

GBS was superior to AIMS65 score, clinical Rockall score and complete Rockall score in identifying the patients who are likely to need blood transfusion sensitivity $56.3 \%$, specificity $87.5 \%$, cutoff $>11.0$, while AIMS65 score was superior to GBS, clinical Rock score and complete Rocall score in prediction of unfavorable outcomes, namely risk of need for ICU admission "Cuttoff >2.0, sensitivity $86.4 \%$ specificity $96.1 \%$ ", need for interventional endoscopy "cutoff $>2.0$, sensitivity $55.8 \%$, specificity $82.4 \% "$, rebleeding in hospital "cutoff > 2.0, sensitivity $92.7 \%$, specificity $95.0 \% "$, death in hospital"cutoff $>2.0$, sensitivity $100 \%$, specificity $89.2 \%$ and rebleeding after one week cutoff $>1.0$, sensitivity $100 \%$ specificity $33.7 \%$.

\section{REFERENCES}

1. Abougergi, M. S., Charpentier, J. P., Bethea, E., Rupawala, A., Kheder, J., Nompleggi, D. and Saltzman, J. R. (2016): A prospective, multicenter study of the AIMS65 score compared with the Glasgow-Blatchford score in predicting upper gastrointestinal hemorrhage outcomes. Journal of Clinical Gastroenterology, 50(6): 464-469.

2. Barkun, Alan N. Bardou, M., Kuipers, E. J., Sung, J., Hunt, R. H., Martel, M. and Sinclair, P. (2010): International Consensus Recommendations on the Management of Patients With Nonvariceal Upper Gastrointestinal Bleeding. Annals of Internal Medicine, 152(2):101-113.

3. Bozkurt S., Kose A., Arslan ED., Erodgan, S., Ucbilek E., Cevik I., 
Ayrik C. and Sezgin O. (2015): Validity of modified early warning, Glasow Blatchford, and pre-endoscpic Rockall scores in predicting prognosis of patients presenting to emergency department with upper gastrointestinal bleeding; Scandinavian Journal of Trauma, Resuscitation and Emergneyc Medicine, 23:109-113.

4. Budimir, I., Gradišer, M., Nikolić, M., Baršić, N., Ljubičić, N., Kralj, D. and Budimir Jr, I. (2016): Glasgow Blatchford, pre-endoscopic Rockall and AIMS65 scores show no difference in predicting rebleeding rate and mortality in variceal bleeding. Scandinavian Journal of Gastroenterology, 51(11): 1375-1379.

5. Dworzynski, K., Pollit, V., Kelsey, A., Higgins, B. and Palmer, K. (2012): Management of acute upper gastrointestinal bleeding: summary of Nice guidance. BMJ, 344: e3412-3420.

6. Espinoza-Ríos, J., Aguilar, V. S., Bravo, E. P., Pinto, J. V. and HuertaMercado, J. T. (2016): Comparison between Glascow-Blatchford, Rockall and AIMS65 scores in patients with upper gastrointestinal bleeding in a hospital in Lima, Peru. Revista de gastroenterologia del Peru: organo oficial de la Sociedad de Gastroenterologia del Peru, 36(2): 143-152.

7. Hwang, J. H., Fisher, D. A., BenMenachem, T., Chandrasekhara, V., Chathadi, K., Decker, G. A. and Fukami, N. (2012): The role of endoscopy in the management of acute non-variceal upper GI bleeding. Gastrointestinal Endoscopy, 75(6): 11321138.

8. Hyett, B. H., Abougergi, M. S., Charpentier, J. P., Kumar, N. L., Brozovic, S., Claggett, B. L. and Saltzman, J. R. (2013): The AIMS65 score compared with the GlasgowBlatchford score in predicting outcomes in upper GI bleeding, Gastroientst ENdosc, 77: 551-557.

9. Kalkan, Ç., Soykan, I., Karakaya, F., Tüzün, A. and Gençtürk, Z. Bı. (2017): Comparison of three scoring systems for risk stratification in elderly patients with acute upper gastrointestinal bleeding. Geriatr Gerontol Int, 17: 575-583.

10. Kim, M. S., Choi, J. and Shin, W. C. (2019): AIMS65 scoring system is comparable to Glasgow-Blatchford score or Rockall score for prediction of clinical outcomes for non-variceal upper gastrointestinal bleeding. BMC Gastroenterology, 19(1): 136-140.

11. Laine, L. (2016): Risk Assessment Tools for Gastrointestinal Bleeding. Clinical Gastroenterology and Hepatology, 14.11: 1571-1573.

12. Monteiro, S. Concalves, T.C., Magalhaes, J. and Cotter, J. (2016): Upper gastrointestinal bleeding risk scores: who, when and why? World J Gastroinest Pathphysiol, 7 (1): 86-96.

13. Nahon, S., Hagège, H., Latrive, J. P., Rosa, I., Nalet, B., Bour, B. and Henrion, J. (2012): Epidemiological and prognostic factors involves in upper gastrointestinal bleeding: results of a French prospective multicenter study. Endoscopy, 44: 998-1008.

14. Park, S. M., Yeum, S. C., Kim, B. W., Kim, J. S., Kim, J. H., Sim, E. H. and Choi, H. (2016): Comparison of AIMS65 score and other scoring Systems for Predicting Clinical Outcomes in Koreans with nonvariceal upper gastrointestinal bleeding. Gut Liver,10(4): 526-531.

15. Robertson, M., Majumdar, A., Boyapati, R., Chung, W., Worland, T., Terbah, R. and Vaughan, R. (2016): 
Risk stratification in acute upper GI bleeding: comparison of the AMIS65 score with the Glosgow-Blatch for and Rockall scoring systems gastroineste Endosc, 83 (6): 1151-1160.

16. Saltzman, J. R., Tabak, Y. P., Hyett, B. H., Sun, X., Travis, A. C. and Johannes, R. S. (2011): A simple risk score accurately predicts in-hospital mortality, length of stay, and cost in acute upper GI bleeding. Gastrointest ENdosc, 74: 1215-1224.

17. Stanley A J, Laine L, Dalton Harry R, Ngu Jing $H$, Schultz Michael andAbazi. $\quad R$ (2017): Comparison of risk scoring systems for patients presenting with upper gastrointestinal bleeding: international multicentre prospective study BMJ, 356: i6432-6443.

18. Stanley, A. J. (2012): Update on risk scoring systems for patients with upper gastrointestinal haemorrhage. World Journal of Gastroenterology, 18(22): 2739-2744.

19. Stanley, Adrian J. (2012): Update on risk scoring systems for patients with upper gastrointestinal haemorrhage.
World Journal of Gastroenterology: WJG 18.22: 2739.

20. Tham, T. C. K., James, C. and Kelly, M. (2006): Predicting outcome of acute nonvariceal upper gastrointestinal haemorrhage without endoscopy using the clinical rockall score. Postgrad Med J, 82: 757-759.

21. Thandassery, R. B., Sharma, M., John, A. K., Al-Ejji, K. M., Wani, H., Sultan, K. and Butt, M. T. (2015): Clinical applica on AIMS65 scores to predict outcomes in patients with upper gastrointesnal hemorrhage: clin Enbdoc., 48: 380- 384 .

22. Yaka, E., Yılmaz, S., Özgür Doğan, N. and Pekdemir, M. (2015): Comparison of the Glasgow-blatchfor and AIMS658 scoring systems for risk straca on in upper gastrointestinal bleeding in the emergency department. Acad emerg Med., 22: 22-30. 


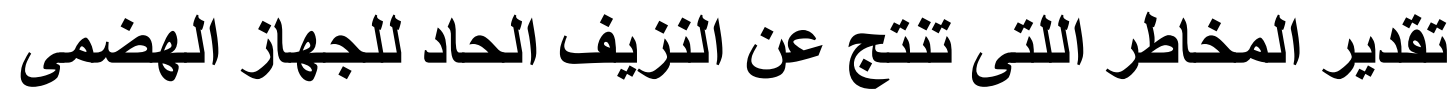

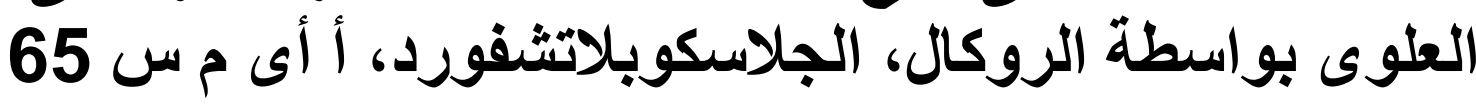
عمرو عبد المنعم المهر، محمد عامر عفيفى، شريف على عبد العزيز قسم الكبد والجهاز الهضمى والأمراض المعدية، كلية الطب، جامعة الأزهربالقاهرة مستثفى معهز ناصر للبحوث والعلاج

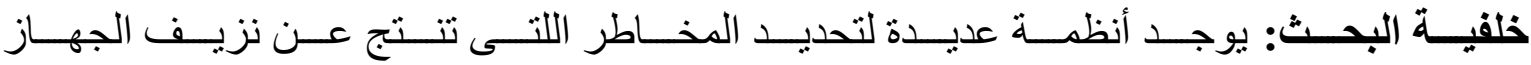

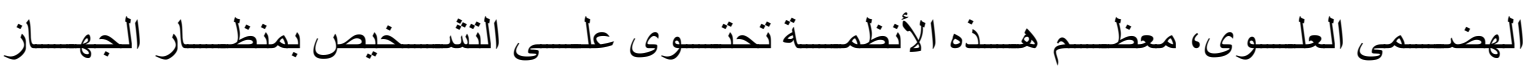

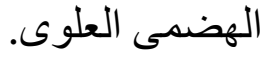

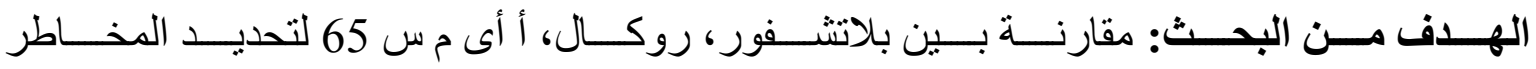

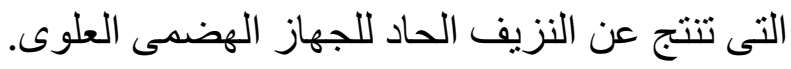

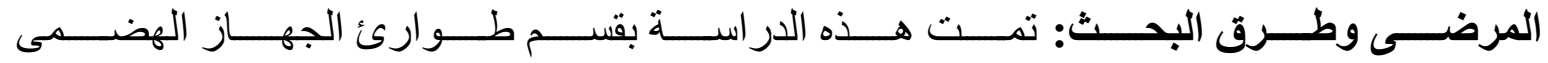

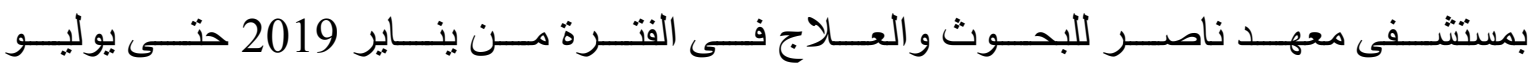

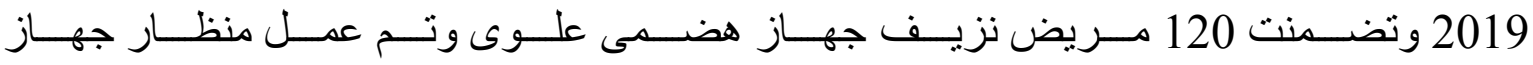

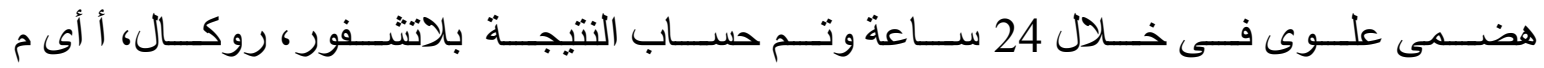

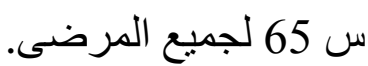

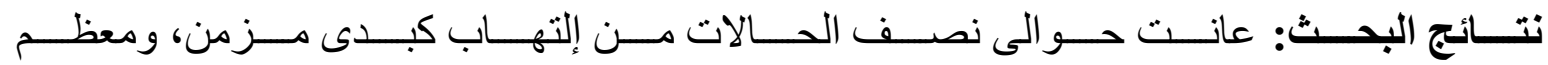

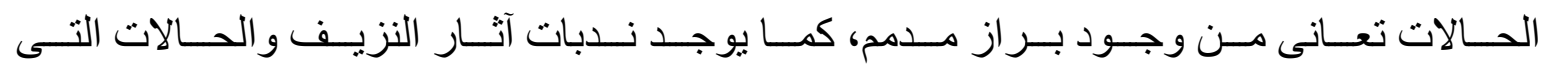

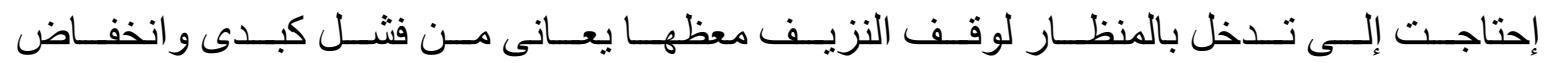
ضغط الدم و إغماء ووجود أمر اض مزمنة أخرى وسوء في النتائج المعطلية.

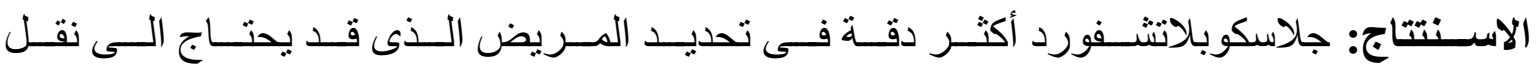

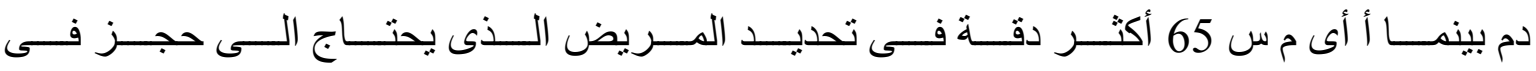

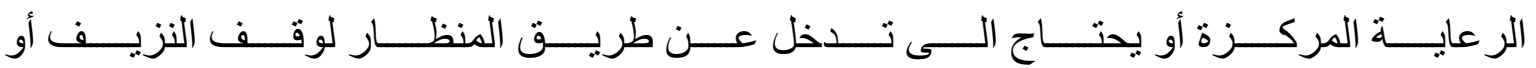

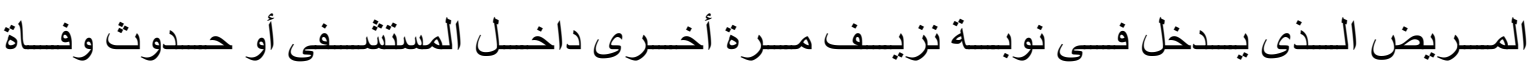

